\section{US Mars lobby \\ Washington}

THE "Mars underground", a network of enthusiasts dedicated to persuading the US government to support a manned mission to Mars, has again been raising its voice in public, pressing its case for a permanent base on Mars to the National Commission on Space. The signs are that it is being taken seriously.

The movement is made up both of university-based researchers and many in the National Aeronautics and Space Administration (NASA). As long ago as the early 1960 s, NASA commissioned studies to investigate the feasibility of Mars missions, but enthusiasm waned as manned Moon landings became routine and the Apollo programme was brought to a premature close. But now the Mars underground seems to have found new strength.

Mr Leonard David, director of research of the National Commission on Space, is one of the biggest supporters of Mars ventures. He is to present a report on the future of the civilian space programme to the President and Congress by March 1986. The commission, appointed by President Reagan earlier this year, was explicitly told to take a bold long-term view, and it seems to be doing just that. It will look at options for the period to 2035 or even beyond, and will be taking a hard look at the Mars base plan as well as at proposals for a manned lunar base

David points out that Mars has for many years been a vague long-term goal for NASA. With the shuttle now working at

\title{
gathers strength
}

least tolerably well and a space station apparently not too far off. the question that will arise is what they should be used for - whence the "case for Mars" group. which presented a 150-page summary of its plans to the commission last week at Stanford. California.

The group expects to use the first permanent manned bases on Mars established between 2010 and 2020: before then. though, bases may have been established on Mars's moons. Phobos and Deimos. which may contain enough water to use as a source of hydrogen and oxygen for fuel. The effort would be international and, after initial unmanned exploratory missions, the first crew of about 15 people would arrive for a ground spell of duty of up to two years

The group lays much stress on using martian materials wherever possible, and notes that the martian atmosphere contains a high proportion of carbon dioxide. which could supply many essential needs for a permanent base.

The National Commission now has to weigh these ambitious plans against the rather less exciting lunar base plan. According to David, a lunar base might be a spin-off from a Mars base plan but is not generally thought to be an essential precursor. But there is one extra factor arguing for a Mars effort which could prove the most important of all: the Soviet Union has already spoken of plans for a manned Mars mission as early as the middle of next decade.

Tim Beardsley

\section{Parallel computers}

\section{GE aims at super-array contract}

\section{Schenectady, New York}

Giant General Electric (GE) is in the final stages of negotiating a contract with the US Department of Defense to complete the development and to begin the construction of what could be the world's most powerful computer

The multimillion dollar project. a collaboration between $G E$ 's research and development centre here and the Artificial Intelligence Laboratory at the Massachusetts Institute of Technology (MIT). is for the construction of a machine with no fewer than 256,000 processors. Those responsible for the project wryly note that the new machine, called the Cross Omega Connection Machine, will have 100 times as much computing power as all the computers now installed at the centre.

The practical objective of the development is to construct a computer capable of processing in parallel the information in each picture element (pixel) of a standard 500 by 500 cell image. Suitably miniaturized. such a system could be carried by spacecraft or tanks and could make intelli- gent decisions about the best response to incoming signals in video form.

The speed of the parallel array will be phenomenal - one million million operations a second. GE says that the architecture of the machine will be entirely novel. and that it will represent a milestone in the development of computing machinery. But the construction of the processors is also novel. By means of Very Large Integrated Circuit techniques, 64 processors will be incorporated on each of 4.000 semiconductor chips. By the use of optical lithography. GE claims that it now has in production at its plant at Research Triangle Park. North Carolina, integrated circuits with linewidths of only 1.2 micrometres, and that the research laboratory has made microcircuits with linewidths of 0.4 micrometres.

But Dr Phil Lewis, head of GE's computer science branch at Schenectady says: "We have to make a whole new computer science for this machine. And nobody knows how to do it." Bill Johnstone
Remote sensing France puts trust in SPOT

SPOT 1. the first of two French observaltion satellites, is to be launched by Ariane on 11 January. only a few weeks late despite the failure of the last Ariane launch on 13 September. Arianespace, the commercializer of Ariane. will be crossing its fingers that adjustment to the design of a valve in the third stage will seal the leak of liquid hydrogen that caused the failure. So will the French space agency CNES. which has designed SPO'T and which hopes it will steal the thunder from the US Landsat series of satellites.

CNES claims that twin high-resolution imaging instruments on SPOT 1. operating in the visible and near infrared. will bo capable of identifying details down to about 10 metres, compared with the 30 metres of the last Landsat (Landsat 4) launched in July 1982).

CNES emphasizes, however, that the great innovation of SPOT is not so much its resolution as an ability to look away from the vertical. By this means, the satellite can in two passes some 90 minutes apart image the same Earth region from different angles, thus generating threcdimensional images. Simulations of such SPOT images have been made from aircraft, and they are certainly spectacular to view. These images should contain quite new cartographic information on vast regions of the more inaccessible parts of the Earth, and pose new challenges for information processing.

CNES has established a number of ground stations for receiving SPOT data. at which the data will be processed into directly usable images. In France, the principal station will be at Toulouse, where SPOT was designed and where all SPOT imagery is to be kept. A company called Spot Image has been established to sell and distribute images.

SPOT 1 will be accompanied into space, if all goes well, by the first Swedish scientific satellite, VIKING.

Subsequent Ariane launches are planned for February (two communications satellites, one for the US GTE Spacenet Corporation and one for the Brazilian government) and March (Intelsat V). Five additional launches are planned for 1986. Arianespace has also announced that despite its September setback, three institutions have since purchased future Ariane launches: one to orbit the first Luxembourg television satellite, which will broadcast to most of Europe, and one for a communications satellite for INMARSAT (the International Maritime Satellite Organisation).

These orders bring the total number of launch contracts of Arianespace to 37. of which 25 remain to be launched, the company says.

Robert Walgate 